the exfoliation of the cuticle being chiefly apparent on the summits of the central papules, and along the convexity of the rings. The scales, however, were obviously nothing more than desiccated epiderma, and very thin; and not, as in the case of lepra, altered in its anatomical structure, and thick and laminated.

This poor girl had been injudiciously treated previously to her application to me; she had taken mercury for the eruption until her mouth had been made sore. Now this was very unnecessary, and might have been attended with serious results in a person of so delicate a constitution; as it was I attribute the tendency to suppurate, which was apparent in some of the papules, to this cause. The duration of the eruption had undoubtedly been prolonged by the mercurialization.

My treatment consisted in the exhibition of the iodide of potassium, in decoction of sarsaparilla, under which she got rapidly well, the eruption subsiding and disappearing in the course of three weeks.

Henrietta-street, Cavendish-square.

$=$

REPORT OF

\section{A RECENT CASE OF CHOLERA SUCCESSFULLY TREATED BY FREQUENT DOSES OF CALOMEL, EFFERVESCENT DRAUGHTS, AND BRANDY.}

\section{By R. BUDD PAINTER, Esq., M.R.C.S.Eng.,} M. \& L.S.A., Westminster.

W. $\mathbf{P}$ - a policeman, aged thirty-two, went on duty, quite well, on the evening of the 8 th inst. At four o'clock the next morning he was suddenly seized with a " pinching pain in his inside," followed quickly by two motions, looking very much like beer. He felt excessively ill, and being very soon relieved from duty, went home, when he had a most copious watery motion. I was not called upon to visit him until one P.M. on the 9th, when he presented the usual signs of collapse, which was evidently proceeding to that of the profoundest kind. He was lying across the bed, with his head hanging over its edge; frequent streams of colourless fluid gushing from the mouth and the rectum, without the least effort; the pulse scarcely perceptible; the hands shrivelled the tongue, nose, cheeks. and extremities cold: the voice nearly gone; and cramps in the legs and belly very bad.

I immediately ordered the legs to be encased in mustard poultices, and a large one also to be placed on the abdomen two grains of calomel to be given every five minutes; an effervescing saline draught, with a good large tablespoonful of brandy, every quarter of an hour; and an ounce of cold water frequently.-Half-past two P.M.: The patient is much improved; sickness and purging not near so frequent; cramps much better; pulse more perceptible; breath \&c. not so cold. To continue the calomel every ten minutes, and an effervescing draught and brandy each quarter of an hour, and to have an ounce of water very often.- Half-past three: On entering the room, I was pleased to see the countenance much more natural; a nice state of reaction coming on; cramps better no dejection since my last visit, and retching only twice. To have beef-tea to drink, instead of water; to continue the calomel every half-hour, and the effervescing draught and brandy every half-hour also.-Five o'clock: Better in all respects; there is no sickness or purging; some slight redness and swelling of gums to be observed. To take the powders every three hours, and the draught every hour or so, with two teaspoonfuls of brandy only.-Eight o'clock: Is quite comfortable; has had one slight, colourless, watery dejection, but no sickness or retching; the lips, tongue, and other parts have regained their natural warmth; the voice and pulse are much stronger; the eyes brighter; the gums evidently affected, but the face is slightly flushed, the superficial veins of the head prominent, and there is a little headache. The brandy to be left off; the powders to be continued every four hours, as also the effervescing draughts; the head to be kept moderately raised on the pillow, and to be frequently bathed with cold water.-Eleven o'clock: Going on admirably. To continue the same remedies.

August 10th.-Half-past eight A.M.: Has passed a tranquil night, and had two small bilious motions, but no sickness pulse 90, intermitting every few beats; no headache or heat of the skin; voice strong, and has passed two ounces and a half of urine this morning; the system is affected by the mercury, but not too much so. Omit the calomel; go on with effervescing draughts; and take beef-tea and arrowroot.-
Seven P.M.: Doing well in every respect; has had another small bilious motion, and passed half a pint of urine.

11 th.-Is cheerful and comfortable; has had no dejection; is excessively weak, but pulse (76) does not intermit to-day; relishes the beef-tea \&c. To have six drachms of castor oil.

12th.-Had two bilious evacuations after the castor oil. Convalescent.

To those who have not tried the above mode of treatment, I can confidently recommend it, not only because it was evidently beneficial in this case, but for the reason, that during the epidemic of last autumn, I found, after trying many plans, that this was the most successful; and my field of observation was by no means small, as medical officer to the parish of St. Margaret, Westminster. The chief caution in treatment of the above kind is to watch the effects very carefully, and leave off the calomel and brandy gradually, as the favourable symptoms arise. I should observe, that in the above case there was no circumstance that could suggest a thought concerning contagion or infection.

Storey's-gate, St. James's-park, Aug. 12, 1850.

P.S.-I find that the friends of the patient gave him more brandy than $I$ ordered, and that he must have had little short of a pint from first to last.

\section{ZRevíngs and Notíces of ZBooks.}

Researches on Mxgnetism, Heat, Light, Crystallization, and Chemical Attraction in their Relations to the Vital Force. By Karu Baron Von Reichenbach, Ph. D. Translated and Edited, \&c., by William Gregory, M.D., F.R.S.E., Professor of Chemistry in the University of Edinburgh. London: Taylor, Walton, \& Co. 1850. 8vo. pp.463, with Three Plates.

True has to show whether the labours of the Baron Von Reichenbach, as recorded in the work we are now about to notice, will bestow upon him an immortality of scientific renown connected with one of the most remarkable series of physico. physiologic investigations ever undertaken, or stamp him as one of the most mistaken and deluded of mortals the world has ever seen. Between wis snotheosis in the temple of nhilosophy, with a mural tablet beside those of Newton, Hunter, and Davy, and one in the calendar of unmitigated yet remarkable delusions, there is no place for the scientific and noble owner of the Schloss Reisenberg: one or the other must be his lot, according as to whether he is proved to be a truthful or a mistaken investigator. If the former, the memory of Reichenbach can never perish from the brightest page in the Archives of Science; if the latter, it will stand as a beacon to warn others from the quicksands of error and fatuity, even higher than the many by which the world has yet had the fortune to be guided. Such being the position of the author, we feel no little responsibility in sitting down to our present task, the more so, because it is one which relates to the consideration of certain asserted facts, of which we confess we have not the slightest practical experience; nor, moreover, are we acquainted with the result of any such experience which has fallen to others, save Reichenbach himself, or at most, alone with that, afforded by the appendix of Dr. Gregory to the present work.

A vast body of novel assertions has been brought before the world, and inquiry, conducted alone on scientific principles, can vouch for or reject them. That they are worthy of such inquiry, no one can doubt, seeing that, according to Dr. Gregory, the qualifications of the author are of the highest kind.

"He possesses a thorough scientific education, combined with extensive knowledge. His life has been devoted to science, and to its application to the practical purposes of mankind. He is known as a distinguished improver of the iron manufacture in his native country, Austria. $\mathrm{He}$ is a thorough practical chemist, and by his well-known researches on tar, has acquired a very high position. But in geology, physics, and mineralogy, he has been equally active. In particular, he is the highest living authority on the subject of meteorites or aërolites, of which remarkable bodies he pos- 